\title{
A COLABORAÇ̃̃O FACILITANDO O PROCESSO DE DIFUSÃO DAS EXPERIÊNCIAS VIVIDAS NO PROGRAMA PROFESSORES PARA O FUTURO: RELATOS DE EXPERIÊNCIAS
}

\author{
COLLABORATION FACILITATING THE DIFFUSION PROCESS OF THE \\ EXPERIENCES LIVED IN THE TEACHERS FOR THE FUTURE PROGRAM: \\ REPORT ON THE TEACHING EXPERIENCES
}

\author{
Marize Lyra Silva PASSOS ${ }^{1}$ \\ Azenaide Abreu Soares VIEIRA ${ }^{2}$ \\ Conceição de Maria Cardoso $\operatorname{COSTA}^{3}$
}

RESUMO: Este trabalho faz um breve relato do processo de difusão dos conhecimentos adquiridos pelos professores brasileiros durante a fase final do curso na Finlândia: VET (Vocational Education and Training) Teachers for the Future - Professional Development Certificate - Cohort III (2016). Este processo teve como base a cooperação gerada entre diversos participantes do programa. Para poder realizar esta difusão foram planejadas e executadas palestras e oficinas sobre aprendizagem ativa e aprendizagem centrada no aluno que envolveram quinze professores e atingiram 407 participantes. Estas ações visaram levar nossos colegas a entender um pouco mais sobre como funciona a educação finlandesa e a construir caminhos para melhorar o ensino e aprendizagem em nossos Institutos. A metodologia utilizada baseou-se no estabelecimento de redes com os membros do grupo, bem como com outros colegas do VET III e do VET II, com o objetivo de gerar apoio às inovações propostas e à geração de novas ideias. Os resultados mostraram que mudanças na educação brasileira são possíveis, mas requerem um longo período de imersão em práticas ativas de aprendizagem.

PALAVRAS-CHAVE: Aprendizagem ativa. Colaboração. Educação finlandesa.

ABSTRACT: This paper reports on the process of diffusion of the knowledge acquired by the teachers during the final phase of the VET (Vocational Education and Training) Teachers for the Future - Professional Development Certificate - Cohort III course (2016) in Finland. This process was based on the cooperation generated among several participants of the program. In order to carry out this diffusion, lectures and workshops on active learning and student-centered learning involving fifteen teachers and 407 participants were planned and implemented. These actions have aimed to get our

\footnotetext{
${ }^{1}$ Instituto Federal do Espírito Santo (IFES), Vitória - ES - Brasil. E-mail: marize@ifes.edu.br.

${ }^{2}$ Instituto Federal de Educação, Ciência e Tecnologia de Mato Grosso do Sul (IFMS), Campo Grande - MS Brasil. Professora Pesquisadora do Programa MAES. Participante do Programa VET III - Teachers for the Future e do Programa FiTT - Finnish Training Trainners. Doutora em Estudos Linguísticos pela Universidade Estadual de São Paulo. E-mail: azenaide.vieira@ifms.edu.br

${ }^{3}$ Instituto Federal de Educação, Ciência e Tecnologia de Brasília (IFB), Brasília - DF - Brasil. Professorapesquisadora do Programa MAES. Doutora em Geotecnia pela Universidade Federal de Brasília. Participante do Programa VET III - Teachers for the Future. E-mail: conceicao.costa@ifb.edu.br.
}

RIAEE - Revista Ibero-Americana de Estudos em Educação, Araraquara, v. 13, n. esp1, p. 570-575, maio 2018. E-ISSN: $1982-5587$. 
colleagues to understand a bit more about how the Finnish education works and to construct ways to improve teaching and learning in our Institutes. The methodology used was based on networking with group members as well as with other VET III and VET II colleagues in order to support pro-active innovations and the generation of new ideas. The results suggest that changes in Brazilian education are possible, but require a long period of immersion in active learning practices.

KEYWORDS: Active learning. Collaboration. Finnish education.

\section{Introdução}

A Finlândia é apontada pela Organização para Cooperação e Desenvolvimento Econômico (OCDE) como um dos líderes mundiais em desempenho acadêmico, e se destaca pela igualdade na educação, alta qualificação de professores e por constantemente repensar seu currículo escolar; isso tornou a educação finlandesa um case de sucesso, o que levou diversos países a dedicarem especial atenção a sua educação. Tal fato levou o governo brasileiro a aproximar-se desse país nórdico, realizando uma parceria que visou capacitar professores brasileiros da Rede Federal de Educação Profissional e Tecnológica (RFEPT). Esta iniciativa foi coordenada pelo Núcleo Estruturante da Política de Inovação (NEPI/SETEC), que planejou e implantou o programa Professores para o Futuro, realizado graças a uma parceria entre o Ministério da Educação, o CNPq e instituições finlandesas. O programa teve por objetivo selecionar propostas para apoio financeiro a projetos que visassem contribuir significativamente para o desenvolvimento científico, tecnológico e de inovação do País.

A primeira chamada pública do Programa Professores para o Futuro $(\mathrm{CNPq}$ SETEC/MEC No 015/2014) foi realizada no ano de 2014 e ofertou 60 vagas para profissionais pertencentes ao quadro de pessoal permanente de Instituição da RFEPCT. Esses profissionais foram capacitados durante cinco meses em uma das seguintes instituições: Hämk University of Applied Sciences (HAMK), HAAGA-HELIA University of Applied Sciences (HAAGA-HELIA) e TAMK University of Applied Sciences (TAMK). A segunda chamada ocorreu ainda no ano de 2014 (CNPq - SETEC/MEC No 041/2015), para o envido de 36 professores no ano de 2015 para serem capacitados, também, nas universidades de HAMK, HAAGA-HELLIA e TAMK, durante cinco meses. A terceira e última chamada, ocorreu no final do ano de 2015 (CNPq - SETEC/MEC No 026/2015), e capacitou 48 professores durante três meses nas universidades de HAMK e TAMK. 
A execução do programa foi estruturada em duas etapas: a primeira consta da oferta de capacitação pelas Universidades de Ciências Aplicadas finlandesas e a segunda na execução de projetos na instituição de origem do professor, por até 5 (cinco) meses, no Brasil. Nesta fase no Brasil os professores deverão, também, executar pelo menos uma ação de multiplicação dos conhecimentos adquiridos.

Com base na proposta de execução de ações de multiplicação de conhecimentos, vários professores que participarão da terceira chamada do Programa Professores para o Futuro durante o ano de 2016 juntaram-se para planejar e executar uma série de atividades que envolveram a execução de palestras, minicurso e um curso piloto no qual foi possível divulgar um pouco do que foi visto e vivido por estes professores. Estas atividades ocorreram nos estados do Espírito Santo e Mato Grosso do Sul, e atingiram aproximadamente 407 educadores, gerando uma forte rede de contatos entre os participantes do programa.

\section{A Etapa Finlandesa}

Durante a etapa que ocorreu na Finlândia os professores participaram do curso VET Teachers for the Future - Professional Development Certificate - Cohort III, e nele puderam ter uma experiência única de vivenciar a execução de um curso totalmente planejado e executado, tendo o aluno como o centro do processo de aprendizagem e baseado em metodologias ativas. Segundo Michael (2006), a aprendizagem ativa é o processo no qual os alunos se envolvam em atividades que os obriguem a refletir sobre ideias e como eles estão usando essas ideias. Ela exige que os alunos avaliem regularmente seu próprio grau de compreensão e habilidade em lidar com conceitos ou problemas em uma determinada disciplina.

Já a aprendizagem centrada no aluno é uma abordagem instrucional na qual os alunos influenciam o conteúdo, atividades, materiais e ritmo de aprendizagem. Este modelo de aprendizagem coloca o aluno no centro do processo de aprendizagem, e o professor fornece aos alunos oportunidades para aprender de forma independente. Esta abordagem inclui técnicas como utilização de problemas abertos e problemas que exigem pensamento crítico ou criativo, e envolve os estudantes em simulações, aprendizagem cooperativa (baseada em equipe), etc. Essa abordagem, se implementada corretamente, pode levar a uma maior motivação para aprender, maior retenção de conhecimento, uma

RIAEE - Revista Ibero-Americana de Estudos em Educação, Araraquara, v. 13, n. esp1, p. 570-575, maio 2018. E-ISSN: $1982-5587$. 
compreensão mais profunda e atitudes mais positivas em relação ao assunto que está sendo ensinado (MICHAEL, 2006).

\section{A Etapa Brasileira - ações de multiplicação}

Durante a execução da etapa brasileira da terceira oferta do Programa Professores para o Futuro os professores trabalharam mais intensamente na perspectiva de criar redes de contatos mais amplos e duradouros; isso permitiu que diversas ações fossem realizadas de forma colaborativa com colegas de outros estados, bem como com colegas de outras ofertas do mesmo programa. Na visão de Abegg e Bastos (2010, p. 211), a colaboração "[...] pressupõe que dois ou mais indivíduos trabalham conjuntamente, trocando ideias e experiências entre si, ou seja, interagindo dialógico-problematizadoramente, surgindo como fruto da interação entre eles, novos conhecimentos, onde ambos são favorecidos".

O grupo responsável por estas ações de difusão foi formado por professores de diferentes localidades do país, Brasília, Espírito Santo e Mato Grosso do Sul, este foi um de nossos desafios, mas após alguma organização conseguimos organizar os nossos contatos e desenvolver o trabalho colaborativo.

De acordo com cada realidade, organizamos alguns momentos para compartilhar a experiência com os outros professores, alunos e comunidade relacionada com cada Instituto Federal. Esses momentos tinham o objetivo de difundir o modelo educacional finlandês e convidar os participantes a estabelecerem redes com o nosso grupo, a fim de refletir sobre como melhorar o ensino baseado em competência e alinhar práticas pedagógicas no contexto educacional brasileiro. A seguir será descrita a realização de algumas destas atividades, nas quais a autora deste relato esteve envolvida.

Quadro 1: Atividades de divulgação sobre o Programa Professores para o Futuro e sobre a educação finlandesa

\begin{tabular}{|l|l|l|}
\hline \multicolumn{1}{|c|}{ Ação } & \multicolumn{1}{|c|}{ Envolvidos } & \multicolumn{1}{c|}{ Abrangência } \\
\hline $\begin{array}{l}\text { Oficina de aprendizagem ativa: a } \\
\text { experiência educacional finlandesa } \\
\text { centrada (projeto piloto) }\end{array}$ & $\begin{array}{l}\text { Isaura Alcina Martins Nobre (Ifes) } \\
\text { Jaqueline Maissiat (Ifes) } \\
\text { Marize Lyra Silva Passos (Ifes) }\end{array}$ & 20 participantes \\
\hline $\begin{array}{l}\text { Mesa redonda no IFES, campus de } \\
\text { Serra, para cerca de 40 participantes. }\end{array}$ & $\begin{array}{l}\text { Flávio Lopes da Silva (Ifes) } \\
\text { Marize Lyra Silva Passos (Ifes) } \\
\text { Paulo Sergio dos Santos Junior (Ifes) }\end{array}$ & 40 participantes \\
\hline $\begin{array}{l}\text { Palestra organizada pela HAMK para } \\
\text { divulgar a educação finlandesa nos } \\
\text { Jogos Olímpicos de 2016. e II. O } \\
\text { público foi quase 40 professores. }\end{array}$ & $\begin{array}{l}\text { Izidro dos Santos de Lima Junior (IFMS) } \\
\text { José Luiz Amado de Menezes e Souza (IFF) } \\
\text { Leonardo Emanuel de Oliveira Costa (IFRJ) } \\
\text { Marize Lyra Silva Passos (Ifes) } \\
\text { Rita Rovai Castellan (IFPE) }\end{array}$ & 40 participantes \\
\hline Oficinas de Metodologia de ensino no & Antônio dos Santos Júnior (IFRO) & 12 participantes \\
\hline
\end{tabular}




\begin{tabular}{|c|c|c|}
\hline Ação & Envolvidos & Abrangência \\
\hline $\begin{array}{l}\text { curso de formação profissional, } \\
\text { científica e tecnológica educação no } \\
\text { IFRO, campus Calama - Porto Velho. }\end{array}$ & $\begin{array}{l}\text { Azenaide Abreu Soares Vieira (IFMS) } \\
\text { Conceição de Maria Cardoso Costa (IFB) } \\
\text { Marize Lyra Silva Passos (IFES) }\end{array}$ & \\
\hline $\begin{array}{l}\text { Palestra para alunos do IFMS, campus } \\
\text { de Nova Andradina (alunos do ensino } \\
\text { médio dos cursos Técnicos de } \\
\text { Agricultura e Ciência da Computação) }\end{array}$ & $\begin{array}{l}\text { Azenaide Abreu Soares Vieira (IFMS) } \\
\text { Marize Lyra Silva Passos (IFES) }\end{array}$ & 150 participantes \\
\hline $\begin{array}{l}\text { Workshop com professores de escolas } \\
\text { municipais da cidade de Bonito, Mato } \\
\text { Grosso do Sul. }\end{array}$ & $\begin{array}{l}\text { Azenaide Abreu Soares Vieira (IFMS) } \\
\text { Conceição de Maria Cardoso Costa (IFB) } \\
\text { Marize Lyra Silva Passos (IFES) } \\
\text { Robson Gonçalves Félix (IFMS) } \\
\text { Juliana Campos Sabino de Souza (IFB) }\end{array}$ & 50 participantes \\
\hline $\begin{array}{l}\text { Seminário sobre o modelo de } \\
\text { educação finlandesa para alunos do } \\
\text { Mestrado Profissional em Ciência e } \\
\text { em Educação Matemática } \\
\text { (EDUCIMAT). }\end{array}$ & $\begin{array}{l}\text { Marize Lyra Silva Passos (IFES) } \\
\text { Vicente de Paulo Ferreira Marques Sobrinho } \\
\text { (Ifes) }\end{array}$ & 25 participantes \\
\hline $\begin{array}{l}\text { Seminário sobre o modelo de } \\
\text { educação finlandesa pra professores da } \\
\text { rede municipal do município de Serra - } \\
\text { ES. }\end{array}$ & $\begin{array}{l}\text { Marize Lyra Silva Passos (IFES) } \\
\text { Vicente de Paulo Ferreira Marques Sobrinho } \\
\text { (Ifes) }\end{array}$ & 25 participantes \\
\hline $\begin{array}{l}\text { Workshop com professores e alunos } \\
\text { do XI CONNEPI. }\end{array}$ & $\begin{array}{l}\text { Azenaide Abreu Soares Vieira (IFMS) } \\
\text { Conceição de Maria Cardoso Costa (IFB) } \\
\text { Marize Lyra Silva Passos (IFES) } \\
\text { Robson Gonçalves Félix (IFMS) } \\
\text { Juliana Campos Sabino de Souza (IFB) }\end{array}$ & 20 participantes \\
\hline $\begin{array}{l}\text { Palestra para reitor e Pro-reitores do } \\
\text { IFB, para apresentar as principais } \\
\text { ideias e o trabalho de desenvolvimento } \\
\text { no Brasil. }\end{array}$ & $\begin{array}{l}\text { Conceição de Maria Cardoso Costa (IFB) } \\
\text { Juliana Campos Sabino de Souza (IFB) } \\
\text { Paula Felipe Schlemper de Oliveira (IFB) } \\
\text { Paulo Wanderley (IFB) }\end{array}$ & 10 participantes \\
\hline $\begin{array}{l}\text { Palestra para todos os Pró-reitores de } \\
\text { pesquisa do IFMS, para apresentar as } \\
\text { principais ideias e o trabalho de } \\
\text { desenvolvimento no Brasil. }\end{array}$ & $\begin{array}{l}\text { Azenaide Abreu Soares Vieira (IFMS) } \\
\text { Robson Gonçalves Félix (IFMS) } \\
\text { Izidro dos Santos de Lima Junior (IFMS) }\end{array}$ & 15 participantes \\
\hline Total & 15 envolvidos & 407 participantes \\
\hline
\end{tabular}

Fonte: autores

Para o desenvolvimento de todas as atividades, tentamos gerar uma rede de contato, tanto quanto possível, não só entre os professores da terceira oferta, mais das demais ofertas também. Além disso, durante a construção de nossos projetos individuais estabelecemos parceria e colaboração com outros professores do Instituto Federal.

\section{Conclusão}

Com esta iniciativa, nós aprendemos que atuar como uma equipe não é fácil, mas é necessário. Aprendemos que a colaboração requer confiança, desejos de aprendizagem de forma progressiva, e leva tempo. A confiança e a perspectiva que não sabemos tudo e sempre temos algo para ensinar e aprender. 
O resultado da ideia mostrou que precisamos fortalecer a Rede Federal de Educação Profissional e Tecnológica, bem como mantermos parcerias internacionais que possam ajudar a educação brasileira a se repensar e se reconstruir numa perspectiva mais colaborativa, gerando aprendizagens ativas e significativas.

\section{REFERÊNCIAS}

MICHAEL, Joel. Where's the evidence that active learning works? Advances in physiology education, v. 30, n. 4, p. 159-167, 2006.

ABEGG, Ilse.; BASTOS, Fábio da Purificação de; MÜLLER, Felipe Martins. Ensinoaprendizagem colaborativo mediado pelo wiki do Moodle. Educar em Revista, n. 38, 2010

\section{Como referenciar este relato de experiência:}

PASSOS, Marize Lyra Silva.; VIEIRA, Azenaide Abreu Soares.; COSTA, Conceição de Maria Cardoso. A colaboração facilitando o processo de difusão das experiências vividas no programa professores para o futuro: relatos de experiências. Revista Ibero-Americana de Estudos em Educação, Araraquara, v. 13, n. esp1, p. 570-575, maio 2018. E-ISSN: 1982-5587. DOI: 10.21723/riaee.nesp1.v13.2018.11456

Submetido em: 30/10/2017

Aprovado em: 01/01/2018 